\title{
Isolation and Purification of Rutin from Euphorbia pulcherrima
}

\author{
Shlini P*, Mary Clare H, Teena Magline Immaculate V \\ Department of Biochemistry, Mount Carmel College, Autonomous, Palace Road, Bengaluru - 560052, Karnataka, India. \\ *Corresponding author's E-mail: shlinip1@gmail.com
}

Received: 16-06-2020; Revised: 18-08-2020; Accepted: 26-08-2020.

DOI: $10.47583 /$ ijpsrr.2020.v64i01.008 \begin{abstract}
Flavonoids are compounds derived from plants and have gained much importance over the decades due to their wide spectrum therapeutic potential and minimal toxicity. Rutin is a citrus flavonoid found richly in citrus fruits, nuts and berries. Euphorbia pulcherrima, a member of the Euphorbiaceace family is a well known ornamental plant. It is also known for its medicinal properties due to presence of bioactive compounds and rutin is one such flavonoid. In the present research work, rutin was isolated and extracted from the dried leaves of E.pulcherrima using $80 \%$ methanol. The phytochemical screening of E. pulcherrima revealed the presence of various classes of chemical constituents like alkaloids, steroids, terpenoids, saponins, glycosides, reducing sugar and amino acid. Qualitative analysis of Euphorbia pulcherrima crude extract was performed using TLC. Partially purified sample was further subjected to HPLC for characterization of Rutin in the extract. The result revealed a major peak at 3.178 mins confirming the presence of rutin in the methanolic extract.
\end{abstract}

Keywords: Rutin, Euphorbia pulcherrima, flavonoid, solvent extraction, methanol, TLC, HPLC.

\section{INTRODUCTION}

P oinsettia is economically significant plant types of the assorted family of Euphorbiaceae indigenous to Central America. It was portrayed as another species in 1834. It is especially notable for its red and green foliage and is generally utilized in Christmas flower shows. Wild poinsettias occur from Mexico to Guatemala, growing on mid-elevation, Pacific-facing slopes. One population in the Mexican state of Guerrero is much further inland, however, and is thought to be the ancestor of most cultivated populations. Euphorbia pulcherrima is a shrub or small tree, typically reaching a height of 0.6 to $4 \mathrm{~m}$ (2-16 feet). Euphorbia pulcherrima's splendid red botanical showcase held against rich green foliage has made this species an occasion a top pick. Its engaging introduction of the conventional Christmas hues has so charmed poinsettia that it is currently second just to the Christmas tree as the most well-known occasion plant. ${ }^{1}$

It has been accounted for that Euphorbia has antiarthritis, anticancer, anticonvulsant, antidiabetic, hostile to dermatitis, against skin inflammation, antimicrobial, antispasmodic, antitumor, antitussive properties, hormonal and myelopoietic properties. ${ }^{2-6} \mathrm{E}$. pulcherrima is otherwise called Christ blossom. It is used typically against afflictions, for example, taking after typhoid and gastroenteritis in Kano Nigeria. Due to the presence of bioactive compounds such as reducing sugars, flavonoids, saponins, terpenoids, steroids and glycosides, it has proved to possess high therapeutic potential. ${ }^{1}$

Rutin $\quad\left(3,3^{\prime}, 4^{\prime}, 5,7\right.$-pentahydroxyflavone-3rhamnoglucoside) is a flavanol, bounteously found in plants, for example, energy bloom, buckwheat, tea, and apple. It is an indispensable nourishing part of nourishment stuff. ${ }^{7}$ Rutin, likewise called as rutoside, quercetin-3-rutinoside, and sophorin is a citrus flavonoid glycoside found in buckwheat. ${ }^{8}$ The name 'rutin' originates from the plant Ruta graveolens, which likewise contains rutin. Artificially it is a glycoside including flavonolic aglycone quercetin alongside disaccharide rutinose. It has exhibited various pharmacological functions, including cancer prevention action, cytoprotective, vasoprotective, anticarcinogenic, neuroprotective and cardioprotective functions. ${ }^{9}$

Rutin upgraded the in vitro serum protein binding of S-and R-warfarin. Rutin treatment altogether diminished the end half-existence of S-warfarin by $37 \%$ because of the $69 \%$ expansion in unbound clearance of the S-enantiomer. More or less, when rutin is administered along with other drugs, it potentially decreases the anticoagulant impact of racemic warfarin. ${ }^{10}$ Rutin is abundantly found in Buckwheat and this is used to inhibit oxidative damage in the endothelial cells of the aorta by reducing nitro tyrosine immunoreactivity. Sprouted Buckwheat extracts relieved tension and could shield arterial endothelial damage caused by free radicals. ${ }^{11}$ Sodium rutin sulfate blocked entry of virus and prevented the virus-cell fusion which was brought about due to the interaction of the analog with HIV-1 envelope glycoprotein..$^{12} \mathrm{An}$ independent study, showed that rutin when administered to SW480 tumour cell lines (human colon cancer cell lines), showed less harmful effects on the body and relative organ weight in mice along with an increase of mean survival time of 50 days. ${ }^{13}$ A hydro gel synthesized from rutin, when administered topically on skin lesions of rats, comparatively showed a reduction in the wound area with respect to the control gels. Due to its antioxidant effect in the affected areas there was a significant drop in lipid 
peroxidation and protein carbonyl content along with heightened catalase activity. ${ }^{14}$ As clear from previously mentioned realities, rutin is phytochemical with different therapeutic effects. Rutin, one of the significant constituents of apples, has a wide exhibit of natural activities. Henceforth, rutin can be viewed as an 'indispensable phytochemical' which can be concentrated widely to build up successful wellbeing profile in human to get remedial advantages. ${ }^{15}$

The present investigation aims at isolation, identification and purification of rutin from the leaves of $E$. pulcherrima.

\section{MATERIALS AND METHODS}

\section{Chemicals}

Methanol, Fehling's A and Fehling's B solution, $\alpha$ naphthol, Benedict's reagent, sodium hydroxide, copper sulphate, Nitric acid, Ninhydrin reagent, Dragendroff's reagent, ferric chloride, chloroform, sulphuric acid, glacial acetic acid, ammonia, isopropanol, benzene was procured from Fischer Scientific. TLC silica gel plate $\mathrm{GF}_{254 \text { was }}$ was procured from Merck.

\section{Plant Source}

The leaves of Poinsettia (Euphorbia pulcherrima) were collected from Mount Carmel College garden, Bangalore, Karnataka. India.

\section{Extraction}

The plant extract was prepared from the leaves of Euphorbia pulcherrima. The dust particles were removed by washing under tap water. The leaves of Euphorbia pulcherrima was dried at $40^{\circ} \mathrm{C}$ in the hot air oven and made it into fine powder using the mixer grinder. The coarse powder of Euphorbia pulcherrima $[2.5 \mathrm{~g}(\mathrm{w} / \mathrm{v})]$ was extracted with $80 \%$ methanol using magnetic stirrer for one hour and the extract was obtained by squeezing through muslin cloth and was used for further experimental analysis.

\section{Phytochemical test}

The fresh methanol extract was subjected to various phytochemical screening for the detection of various plant constituents, characterized for their possible bioactive compounds. ${ }^{16}$

Test for carbohydrates: Fehling's test- The sample extract was treated with Fehling's A and Fehling's B solution and heated in a boiling water bath for $5-10$ minutes at $60^{\circ} \mathrm{C}$. Appearances of reddish orange precipitate indicate the presence for carbohydrates. ${ }^{16}$

Molisch's test- The filtrate of the extract was diluted in water and was treated with few drops of alcoholic $\alpha$ naphthol solution in a test tube. Formation of the violet ring at the junction indicates the presence of carbohydrates. ${ }^{16}$
Benedict's test- The filtrate of the extract was diluted in water and was treated with Benedict's reagent and heated in a boiling water bath for 3-5 minutes. Orange red precipitate indicates the presence of reducing sugars. ${ }^{16}$

Test for proteins: Biuret test- Equal volume of $5 \%$ solution of sodium hydroxide and $1 \%$ copper sulphate were added to sample extract. Appearance of pink or purple colour indicated the presence of proteins and free amino acids. ${ }^{16}$

Xanthoproteic test- The extract was treated with few drops of conc. Nitric acid. Formation of yellow color indicates the presence of proteins. ${ }^{16}$

Ninhydrin test- To the extract, $0.25 \% \mathrm{w} / \mathrm{v}$ Ninhydrin reagent was added and boiled for few minutes. Formation of blue color indicates the presence of amino acid. ${ }^{16}$

Test for alkaloids- A small portion of the sample extract was stirred separately with a few drops of dilute hydrochloric acid and filtered. The filtrate was carefully tested with Dragendroff's reagent.

Dragendroff's test- The filtrate was treated with Dragendroff's reagent (solution of potassium bismuth iodide). Formation of red precipitate indicates the presence of alkaloids. ${ }^{16}$

Test for tannis- Small quantity of sample extract was taken separately in water and tested for the presence of tannins with $5 \%$ ferric chloride solution. Appearance of violet color indicates the presence of tannins.

Test for flavonoids- On addition of sodium hydroxide solution to the sample extract, blue or violet coloration indicates anthocyanins, yellow coloration indicates flavanones and yellow or orange coloration indicates flavonoids. ${ }^{17}$

Test for terpenoids- To the sample extract, chloroform and concentrated sulphuric acid was added and checked for reddish brown coloration for the confirmation of terpenoids. ${ }^{17}$

Test for steroids: Libemann- Burchard reaction- Sample was mixed with chloroform. To this acetic acid and few drops of concentrated sulphuric acid was added from the side of the test tube. First red, then blue and finally green color should appear indicating the presence of steroids. ${ }^{16}$

Test for glycosides: Cardiac glycosides (Keller Killani test) - To the extract, glacial acetic acid, ferric chloride and concentrated sulphuric acid were added. Appearance of reddish brown color at the junction of the two liquid layers indicates the presence of cardiac glycosides. ${ }^{18}$

Anthroquinone glycosides (Borntrager's test) - To the extract, dilute sulphuric acid was added, boiled and filtered. To the cold filtrate, equal volume benzene or chloroform was added. The organic layer was separated and ammonia was added. Ammonical layer should turn pink or red for the presence of anthroquinone glycosides. ${ }^{16}$ 
Test for phenols: Ferric chloride test- Extract was treated with few drops of ferric chloride solution. Formation of bluish black color indicates the presence of phenols. ${ }^{16}$

\section{Partial purification of Rutin by thin layer chromatography}

TLC was carried out to segregate rutin present in the methanolic concentrate of Euphorbia pulcherrima. TLC was performed on a silica gel plate (silica gel GF254, Merck). 2$5 \mu \mathrm{L}$ of plant extract was deposited to the origins of TLC plates from the $1.5 \mathrm{~cm}$ of the origin with the help of capillary tubes. After the application of the sample on the plates, the plates were kept in TLC glass chamber (solvent saturated) then mobile phase was allowed to move through adsorbent phase up to $3 / 4^{\text {th }}$ of the plate. The Solvent system used was Isopropanol/water (4:6). TLC plates were visualized under ultraviolet light ( $\lambda 254$ and $366 \mathrm{~nm}$ ). Retention values of the different bands were then calculated using the equation:

\section{$\mathrm{R}_{\mathrm{f}}=$ Distance travelled by component}

\section{Distance travelled by solvent}

\section{Preparative thin layer chromatography}

Silica gel plate was used. The isopropanol/water (4:6) mobile phase solvent system was used for the separation of rutin. The methanol extract from Euphorbia pulcherrima was deposited as a concentrated band $1.5 \mathrm{~cm}$ from the edge of its respective TLC plate and allowed to dry. The TLC plates were placed in the chromatographic chamber. Then the respective spots were scraped and further used for characterization using HPLC.

\section{Identification and Purification by High performance liquid chromatography}

The partially purified rutin from E.pulcherrima was subjected to HPLC technique which was equipped with the binary pump, UV- Vis detector and dynamax C18 column. $20 \mu \mathrm{l}$ sample volume was analyzed throughout and a combination of methanol and water (1:1) was used as a mobile phase with a flow rate of $1.0 \mathrm{ml} \mathrm{min}^{-1}$ and detected at $356 \mathrm{~nm}$ and the run time was 30 minutes. ${ }^{19,20}$

\section{RESULTS AND DISCUSSION}

Rutin is a candidate theraepeutic flavonoid which can be exploited in medicine and nutrition. However, current research has shown its multi-spectrum pharmacological benefits for the treatment of various chronic diseases, such as cancer, diabetes, hypertension, and hypercholesterolemia. ${ }^{21}$

In this study, rutin was isolated from the leaves E.pulcherrima. This plant is easily available in the market and it possesses wide range of phytoconstituents and also widely known for its multiple applications in the pharmacological field and other miscellaneous uses.

\section{Phytochemical analysis}

Methanolic extract of Euphorbia pulcherrima was subjected to phytochemical and pharmacological activities. Their phytochemical screening was performed according to standard protocol which showed the presence of various constituents like terpenoids, tannins, flavonoids, reducing sugars, phenolics, cardiac glycosides and amino acids. ${ }^{16-18}$ Whereas, reports have revealed that crude extract from the aerial parts of E.pulcherrima with the chloroform showed the presence of alkaloids, steroids, terpenoids, saponins, glycosides, reducing sugars and amino acids while ethyl acetate fraction proved the presence of alkaloids, terpenoids, flavonoids, phlobatannins, reducing sugars, beta cyanin and amino acids. ${ }^{22}$

Table 1: Phytochemical screening of the plant samples

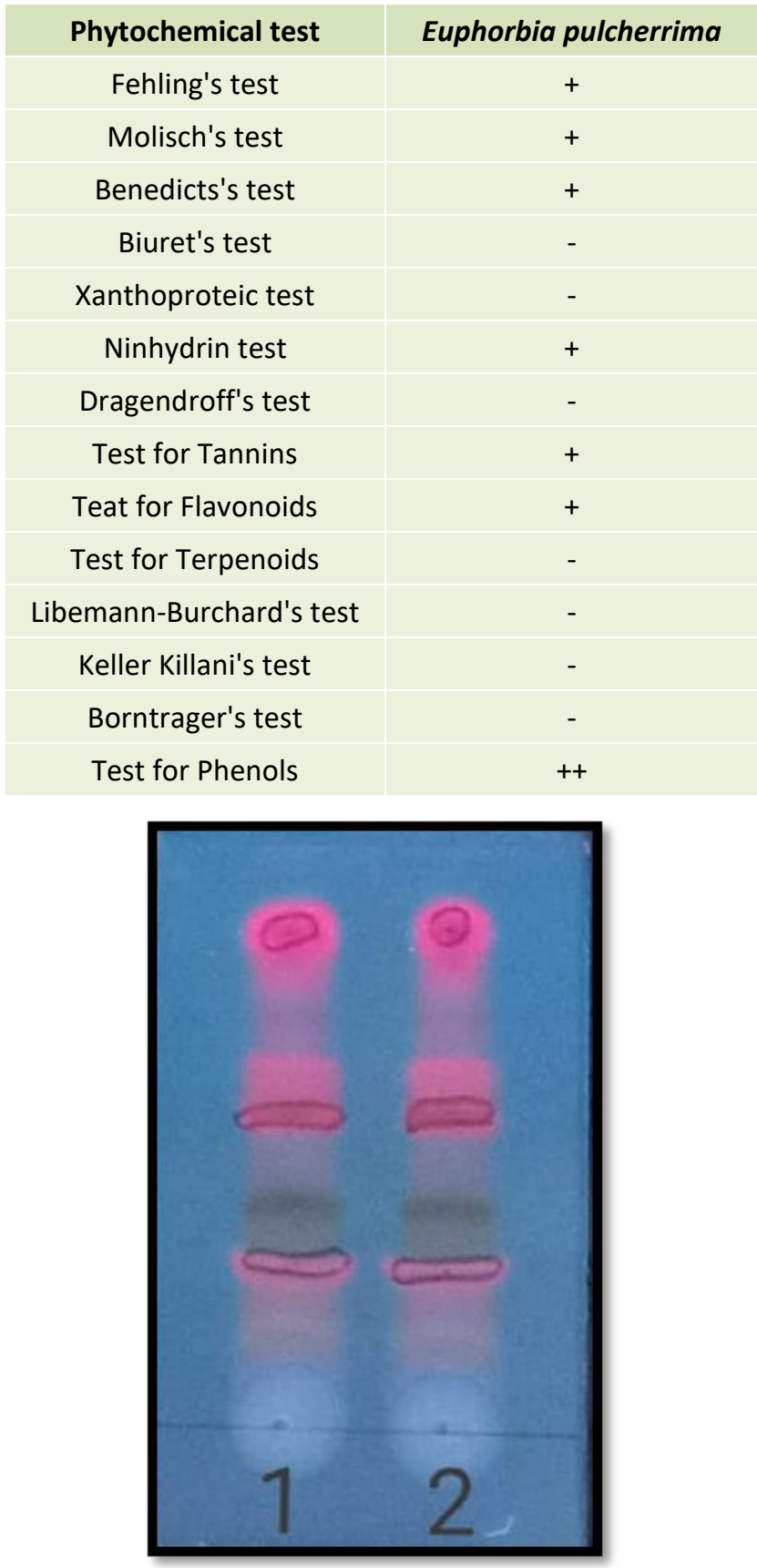

Figure 1: TLC profiling of Rutin under long UV (365nm)

Lane 1 - Crude extract of E.pulcherrima Lane 2 - Crude extract of E.pulcherrima 


\section{Analysis and Partial purification of the plant extracts by TLC}

Thin layer chromatography for the methanolic extract of E.pulcherrima was performed. TLC profiling of this plant extract denoted an imposing result that guided towards the incidence of a number of phytochemicals. Different solvent systems confirmed the presence of diverse potent biomolecules in these plants. TLC investigation delivers an important information about the polarity of the chemical constituents, in such a way that compound displaying high $R_{f}$ value in the less polar solvent system possess lesser polarity and the compound with less $R_{f}$ value possess higher polarity. These potent biomolecules were further analysed using HPLC.

Qualitative analysis of Euphorbia pulcherrima crude extract was performed using TLC. Under visible light yellow color spot was observed whereas under UV light bright orange spot was observed with an $R_{f}$ value of 0.80 and it coincided with the standard rutin of $R_{f}$ value $0.75^{19}$. Rutin in plant samples is identified by its $\mathrm{Rf}$ values, after highlighting the spots in UV light at $\lambda=254 \mathrm{~nm}$. The ultraviolet light has been selected as visualizing agent due to the chromophore $\mathrm{C}=\mathrm{C}-\mathrm{C}=\mathrm{C}-\mathrm{C}=\mathrm{C}-\mathrm{C}=\mathrm{O}$ included in flavones ring. Previous studies have proved that Rutin indicates a yellowish spot in visible light and a yellowbrown fluorescence in UV light. Similar Rf values of 0.82 and 0.78 are obtained when, methanol: glacial acetic acid: formic acid: Water (3: 0.9: 0.9: 0.5) and acetic acid : water $(1: 1)$ are used as solvent systems. ${ }^{23,24}$

\section{Purification and identification by HPLC}

High Performance Liquid chromatography was performed to identify the presence of desired flavonoid compound rutin. This can be done by comparing the retention time of the peaks with that of the standard compounds. Partially purified sample was subjected to HPLC for further purification and identification of Rutin in Euphorbia pulcherrima extract. The ability to predict the chromatographic mobility of a compound under given conditions, is based on its structure and offers many merits in analysis. The elution sequence of flavonoids can be understood by assuming that the compounds are first absorbed on the reversed stationary phase. The illustrated HPLC chromatogram of methanolic extracts of E.pulcherrima determined the presence of rutin.

The sample's chromatogram revealed a major peak at 3.178 mins. On correlating the sample's chromatogram with the standard rutin, it showed that there was a similarity in the peak of 3.690 mins of standard with the major peak of 3.178 mins of sample. ${ }^{19}$ This confirmed the presence of rutin in the sample. Rutin showed a similar retention time of 3.7 during the separation of flavonoids present in Nelumbo nucifera by HPLC. ${ }^{25}$ Polar solvents are preferred such as methanol-water, followed by acetonitrile - water are used for the separation of flavonoids and phenolic acids. Usually, acetic acid /formic acid /phosphoric acid, potassium dihydrogen phosphate, ammonium dihydrogen phosphate, and perchloric acid are added along the solvents. This results in vivid separation and also prevents peak tailing with respect to the phenolic character of the flavonoids. ${ }^{26}$

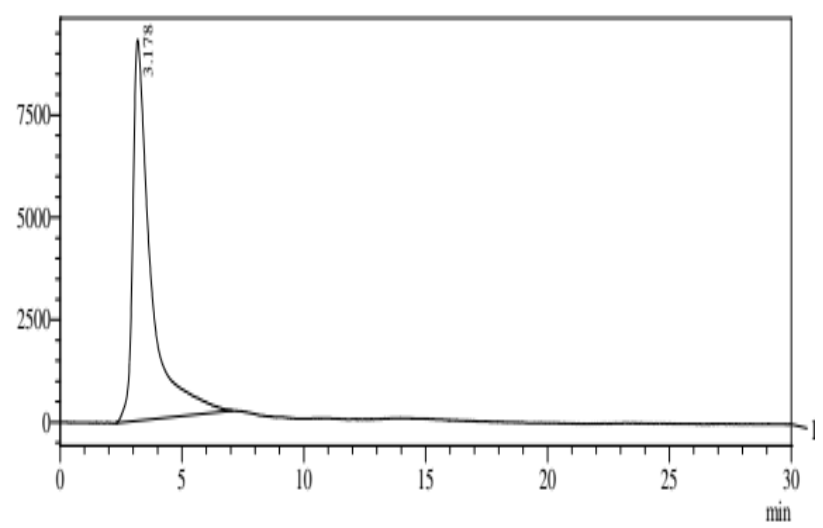

Figure 2: HPLC Chromatogram of partially purified $E$. pulcherrima

Table 2: HPLC profile of rutin isolated from E.pulcherrima

Detector AChl 356nm

\begin{tabular}{|r|r|r|r|r|r|}
\hline Peak\# & Ret. Time & \multicolumn{1}{|c|}{ Area } & \multicolumn{1}{|c|}{ Height } & Area \% & \multicolumn{1}{c|}{ Height \% } \\
\hline 1 & 3.178 & 476461 & 9300 & 100.000 & 100.000 \\
\hline Total & & 476461 & 9300 & 100.000 & 100.000 \\
\hline
\end{tabular}

\section{CONCLUSION}

Recent studies have proven rutin to be a potent biflavonoid having multispectrum pharmacological benefits in treating various chronic disease Currently there are a lot of studies conducted to further enhance its pharmacological properties. A survey was conducted was by the Council for Responsible Nutrition (CRN) in 2014 stated that a huge population in the U.S. consumes dietary supplements. Around $83 \%$ of adults in the U.S. expressed overall confidence in safety, quality and effectiveness of dietary supplements. The growing demand for dietary supplements is expected to bolster the rutin supplement market over the forecast period. Rutin nanocrystals obtained by the smart crystal technology help in enhancing skin penetration. Self-emulsifying drug delivery systems of rutin were prepared by polyethylene glycol (PEG 6000), polyvinylpyrrolidone (PVP K30 and PVP K17) or sodium desoxycholate by co-precipitation method to improve the bioavailability of bioactive compound. Rutin-encapsulated chitosan nanoparticles can be helpful as neuroprotective and readily available to the brain in the treatment of Cerebral Ischemia. Liposome hydrogel can function as potential drug delivery systems to enhance transdermal permeation of the water-insoluble antioxidants such as quercetin and rutin.

Acknowledgement: The authors wish to acknowledge the Department of Chemistry (PG Biochemistry) and the management of Mount Carmel College, Autonomous, Bengaluru for funding and offering their facilities for the analysis. 


\section{REFERENCES}

1. Evens Z, Stellpflug S, Holiday plants with toxic misconceptions, Western Journal of Emergency Medicine, 13(6), 2012, 538-542.

2. Valente C, MJ Ferreira, PM Abreu, M Pedro, F Cerqueira, MS Nascimento, Three new jatrophane-type diterpenes from Euphorbia pubescens, Planta Medica, 69, 2003, 361-366.

3. Luo, H, A Wang, Induction of apoptosis in K562 cells by jolkinolide B. Candian Journal of Physiologyand Pharmacology, 84, 2006, 959965.

4. Ferreira MJ, N Duarte, N Gyemant, R Radics, G Cherepnev, A Varga, J Molnar, Interaction between doxorubicin and the resistance modifier stilbene on multi drug resistant mouse lymphoma and human breast cancer cells, Anticancer Research, 26, 2006, 3541-3546.

5. Eberle MM, C Erb, J Flammer, P Meyer, Dermatitis and conjunctivitis after contact with Euphorbia myrsinites (wolf's milk extract)--a case report, Klin Monatsbl Augenheilkd, 215, 1999, 203-204.

6. Lin LJ, GT Marshall, AD Kinghorn, The dermatitis-producing constituents of Euphorbia hermentiana latex, Journal of Natural Products, 46, $1983,723-731$

7. Harborne J.B. , Nature, distribution and function of plant flavonoids, Progress in clinical and biological research, 213, 1986, 15-24.

8. Kreft S, Knapp M, Kreft I, Extraction of rutin from buckwheat (Fagopyrum esculentum Moench) seeds and determination by capillary electrophoresis, Journal of Agriculture and Food Chemistry, 47(11), 1997, 4649-4652.

9. H Javed, M Khan, A Ahmad, K Vaibhav, M E Ahmad, A Khan, M Ashafaq, F Islam, M S Siddiqui, M Safhi, F Islam, Rutin prevents cognitive impairments by ameliorating oxidative stress and neuroinflammation in rat model of sporadic dementia of Alzheimer type, Journal of Neuroscience, 17, 2012, 340-352.

10. Chan E, Hegde A, Chen X, Effect of rutin on warfarin anticoagulation and pharmacokinetics of warfarin enantiomers in rats, Journal of Pharmacy and Pharmacology , 61(4), 2009, 451458 .

11. Kim DW, Hwang IK, Lim SS, Yoo KY, Li H, Kim YS, Kwon DY, Moon WK, Kim DW, Won MH, Germinated Buckwheat extract decreases blood pressure and nitrotyrosine immunoreactivity in aortic endothelial cells in spontaneously hypertensive rats, Phytotherapy Research, 23(7), 2009, 993-998.

12. Tao J, Hu Q, Yang J, Li R, Li X, Lu C, Chen C, Wang L, Shattock R, Ben $\mathrm{K}$, In vitro anti-HIV and -HSV activity and safety of sodium rutin sulfate as a microbicide candidate. Antiviral Research, 75(3), 2007, 227-233.

13. Alonso-Castro AJ, Domínguez F, García-Carrancá, Rutin exerts antitumor effects on nude mice bearing SW480 tumor, Archives of Medical Research, 44(5), 2013, 346-351.
14. Almeida JS, Benvegnú DM, Boufleur N, Reckziegel P, Barcelos RC Coradini $\mathrm{K}$, de Carvalho LM, Bürger ME, Beck RC, Hydrogels containing rutin intended for cutaneous administration: efficacy in wound healing in rats, Drug Development and Industrial Pharmacy, 38(7), 2012, 792-799.

15. Ganeshpurkar A, Saluja AK, The Pharmacological Potential of Rutin, Saudi pharmaceutical journal, 25(2), 2017, 149-164.

16. Khandelwal KR, Practical Pharmacognosy, Techniques and Experiments. 13th Edition. Nirali Prakashan, Pune, India. 2005

17. Edeoga HO, Okwu DE and Mbaebie BO, Phytochemical constituents of some Nigerian Medicinal plants, African Journal of Biotechnology, (4), 2005, 685-688.

18. Aiyelaagbe, Olapeju, Osamudiamen, Paul, Phytochemical screening for active compounds in Mangifera indica leaf from Ibadan, Oyo State, Journal of Plant Science and Research, 2, 2009, 11-13.

19. Ashok PK and Saini B, HPLC Analysis and Isolation of Rutin from Stem Bark of Ginkgo biloba L, Journal of Pharmacognasy and Phytochemistry, 2(4), 2013 , 68-71.

20. Vachirapatama Narumol, Chamnankid, Busaya, Kachonpadungkitti, Yongsak, Determination of Rutin in Buckwheat Tea and Fagopyrum tataricum Seeds by High Performance Liquid Chromatography and Capillary Electrophoresis, Journal of Food and Drug Analysis, 19, $2011,463-469$.

21. Sharma S, Ali A, Ali J, Sahni JK, Baboota S,Rutin : therapeutic potential and recent advances in drug delivery, Expert Opinion on Investigational Drugs, 22(8), 2013, 1063-79.

22. Abdur Rauf and Naveed Muhammad, Phytochemical and pharmacological evaluation of aerial parts of Euphorbia pulcherrima L 1, Wudpecker Journal of Pharmacy and Pharmacology, 2, 2013, 15-20.

23. Şerban Georgeta, Pop Iulia Ana, Horvath Tünde, Bota Sanda, The isolation and identification of rutin from pharmaceutical products, Analele Universității din Oradea, Fascicula: Ecotoxicologie, Zootehnie și Tehnologii de Industrie Alimentară, 15, 2016, 109114.

24. Doshi GM, Une HD, Quantification of Quercetin and Rutin from Benincasa hispida Seeds and Carissa congesta Roots by Highperformance Thin Layer Chromatography and High-performance Liquid Chromatography, Pharmacognosy Research, 8(1), 2016 ,3742.

25. Naveen P, Lingaraju HB, Anitha, Prasad KS, Simultaneous determination of rutin, isoquercetin, and quercetin flavonoids in Nelumbo nucifera by high-performance liquid chromatography method, International Journal of Pharmaceutical Investigation, 7(2), 2017, 94-100.

26. Stefova, Marina, Stafilov Trajce, Kulevanova, HPLC analysis of flavonoids, Encyclopedia of Chromatography, 2003, 113-119.

\section{Source of Support: None declared.}

Conflict of Interest: None declared.

For any question relates to this article, please reach us at: editor@globalresearchonline.net New manuscripts for publication can be submitted at: submit@globalresearchonline.net and submit_ijpsrr@rediffmail.com 